\title{
Ant Âùress
}

on

\section{HIGH BLOOD PRESSURE:}

\author{
ITS ASSOCIATIONS, ADVANTAGES, AND
} DISADVANTAGES.

Dilivered at the Glasgow Sóuthern Medical Society. BY

SIR WILLIAM OSLER, BART., M.D., F.R.S.,

REGIUS PROIESSOR OF MEDICINE, OXFORD; HONORARY PRESIDENT OF THE SOCIETY.

LIFE is correlated in every way with tension of a certain quality-with a force, a pressure that keeps the atoms whirling in organic circlcs. Lower, beyond a certain point, the pressure with which the blood flows in the medulla, changes the surface tension of the fluid in which a leucocyte swims, or an amoeba crawls, and the atoms of the man, of the leucocyte, and of the amocba soon cease to swing in organic rhythm, and change to that to which all inorganic matter has been attuned since, in the words of Lucretius, "the atoms fell into such a disposition as those whereby our world of things created holds together."

Blood pressure-the force with which the blood circulates-maintains in organic activity every part of the body. With the five factors concerned in its maintenance I need not detain you. The heart pump supplies a force which the elastic coats of the large arteries store to convert an intermittent into a continuous stream. The small artcries act as sluices or taps regulating the supply to different parts. Over the capillary bed the nutritive fluid is distributed. And there is a drainage system of veins and Jymph channels. Life depends on the maintenance of a due pressure in the irrigation fields, to the canals of which Galen first likencd the biood ressels: "So it is with the animal body. Many canals dispersed through all its parts convey to them blood, as those of a rarden convey moisture, and the intervals separating those canals are wonderfully disposed by Nature in such a way that they should neither lack a sufficient quantity of blood for absorption, nor be overloaded at any time with an cxcessive supply." On a liuge scale, one secs this in a land like Egypt, the very life of which depends on the height of the pressure of water, whether in the annual rise of the Nile, or as it is dammed and stored artificiaily.

A man's life may be said to be a gift of his blood pressure, just as Egypt is a gift of the Nile (Herodotus). It is interesting to see at first hand how this pressure is liept up in Egypt by the big dams at the Delta, at Assiut, at Esna, and the monster one at Assouan. When raised $15 \mathrm{ft}$., the last named will give life to another one aud a half million acres of dead sand. Along the Nilo big stcam pumping stations leep certain canals and reservoirs full. For thousands of years, long before dams werc built, the patient fellaheen have baled the water from level to level with a bucket at one end of a crossbcam, counterpoised with a weight at the other. Of the three forces which now keep Egypt watered, gravity, steam, and human muscle, the first is the most important. In the human irrigation scheme there is nothing to correspond with this -incleed, gravity in the circulation of all living things is a great obstacle, to overcome which the pump had, in animals at least, to be introduced. The man with the shadoof working on the banks of the Nile, the immediate agent in the old-fashioned plan of irrigation, represents rather the living capillary cell. And the Nilo mud itself is alive, not alone in the magic potency which gare man his earliest civilization, but in plastic quaiities which enable the fellaheen to build the dylies and clams with canals and rivulets, making every acre a miniature of Egypt itself. In the fields, as in the body, are schemes for distributing the vital fluid, for varying the pressure in different parts, and tivo all-important things are arranged - the final channels of distribution between the cotton rows or the corn are kept free from weeds and obstruc. tions, and provision is made for drainage, for carrying off the surplus water, to prevent dropsy of the soil.
The whole question of blood pressure is tos vast for me to do more than touch upon two points essential to my purpose this evening. The smaller arteries act as stopcoclis -taps which regulate the flow to the vascular areas according to requirements. Under the control of various stimuli - vasomotor, hormonic, physical, and postural-they aro sluice-gates to be open or shut. The mean pressure in them depends less on the forces of the pump than on tho distribution of the blood bulk, the state of the arterial walls, and the state of the capillary bed. So important is distribution that a person may bleed to death into his own vessels, splanchnic or systemic. Hold a hutch rabbit up by the ears, and so much blood accumulates in its splanchnic reservoir that the pressure falls in the smaller arteries of other regions, and the animal dies. The average pressure in the various territories to be irrigated is regulated from the vasomotor centres, just as a man in charge of a big irrigation plant controls the sluices, often nowadays raising or lowering them by simply touching an clectric button. In man a mean arterial pressure is maintained-about 125 to $130 \mathrm{~mm}$. of $\mathrm{Hg}$, and 140 to $160 \mathrm{~mm}$. in persons over 50 . A permanent pressure above $160 \mathrm{~mm}$. may be called high, but we must not forget the great regional variations pointed out by Leonard Findlay and others.

In the capillary lake into which the arterial stream widens the current slows and the pressure lessens, though on the latter point authorities are not agreed. There are probably great variations. The Nile, when in low water, takes ninety days to flow from Lake Victoria Nyanza to the sca. Between Grondokoro and Khartoum it passes through the great capillary lake known as the Sud, and more than one-lialf of the time-forty-six days-is taken to pass this short region. But when in flood it takes only fifty days from Lake Victoria Nyanza to the sea, twenty-eight of which are occupied in passing through the Sud. But it is not mcrely a mattcr of rate-flow and pressure in the capillary bed; there are two other factors of prime importance. In the brief fraction of a second, and in a short quarter to three-quarters of a millimetre of space, the business of life is transacted, for here is the mart or exchange in which the raw and the manufactured articles from the intestinal and hepatic shops are spread out for sale. The endo. thelial capillary cell is not a simple dead membrane under the laws of diffusion, but has an active selective power. Playing the part of a middleman, it is every. where a free trader in the bread stuff of life, oxygen, kut a strong protectionist in certain commodities. Thus the renal capillary cell trades in water, salts, urea, and uric acid, but has a high tariff wall against proteins and sugars. In the secretory glands the selective capacity of the capillary wall must be of the first importance, as here the middleman and the retailer are cheek by jowl, and their shops abut, back to back, opening to different streets. These retail shops, represented by the gland and body colls of the capillary areas, do a roaring trade, partly ii common commodities-water, oxygen, salts - and partly in special goods made up on the spot for the use of the body. Each cell, factory as well as shop, collects a great deal of dust and rubbish, and special provision is made for getting rid of this, part being lumped back into the common river, and part into a special lymphatic drainage system, which keeps the irrigation fields free from weeds and dirt. The transactions which take place between the middle. man (the capillary cell), the factory and shop-people (in the gland or body cell), and the sanitary department (represented by the lymph circulation), are regulated in part by the laws of diffusion and osmosis, and partly by the cell specialists (enzymes of rarious sorts), some of which, for example, enable the liver cells to make bile, others to make glycogen. All this activity is associated with movement. 'The force taking the protein molecule through a capillary cell, through the furnace of a muscle cell to make it appear in the lymph space as sarcolactic acid and other organic compounds, is not simple osmosis; but in its working currents caused by the machinery of the cell must set from blood to lymph stream. Though we know very little about it in the animal body, this $v$ is a fronte, which Galen compared very aptly to a magnet, is not a negligible quantity. We know of its immense power in plants, and I believe botanists o,gree that the force which may lift water to a height of 300 feet or more in a tree is a vis a fronte, and not a vis a tergo. All this is preliminary 
to the main topic of my address, the associations' alvantages, and disadvantages of a high blood pressure.

Some years ago I wrote a short paper with a somewhat paradoxical title: "The advantages of a trace of albumen and a few tube casts in the urine of men over 50 years of age." It was written with the specific object of allaying the unnecessary fears of physicians obsessed with the old idea that the presence of these bodies in the urine always indicated serious and progressive disease of the kidneys This bogey has becn to a large extent replaced by that of high blood pressure, a knowledge of which has filtered to the laity with the usual disastrous results. A good many people are unnccessarily alaimcd, and much nccdless worry and anxiety has been caused. For example, a robust, full-blooded country girl was taken to a physician for some menstrual disturbance, and was told that ber blood pressure was 140, and that the outlook for her was serious. The poor girl, very much depressed, regarded her condition as hopeless, particularly in so far as a married life was concerned. She was a strongly built, plethoric, muscular girl, who only needed the reassurance that with her physique such a pressure was as natural as one of 90 would be in a thin, pale delicate girl.

IVluat are the conditions in which we see permanent ligh pressure, and what are its advantages and disadvantages? For practical purposes wo may consider three groups of cases: Simple high tension, hyperpiesis, without signs of arterial or renal disease; arterio-sclerosis, with the associated high tension, renal, and heart changes; and chronic nephritis, with secondary high pressure, arterio-sclerosis, and heart changes.

\section{Hyperpiesis.}

Hyperpiesis signifies simple bigh pressure without signs of cardio-vascular disease. We have learnt to recognize an average pressure, as taken with ordinary instruments, and the figures given are usually accepted. There are, of course, great variations, usually temporary, but now and again we meet with individuals whose pressure is permanently high-above 180-without, so far as can be ascertained, arterial, cardiac, or renal disease. Of course the difficulty is to exclude internal, not discernible, alterations in the splanchnic and other vessels, since; as is well known, vascular disease may be very localized, but, clinically, the group, well defined and very important, has been carefully studied by Allbutt and others. We see the condition most often in men who work hard, drink hard, and smolie hard, particularly in keen business men with heavy responsibilities, and we see it now and then in neurastlenic and gouty persons. Let me gire a ferv illustrative cases : A man just over 40 years of age, $13 \mathrm{st}$. $7 \mathrm{lb}$. in weight, of life of the greatest possible intensity. Early successful, he life of the greatest possible intensity. Early successful, he "high," as the saying is, smoked eight to ten cigars and several "high," as the saying is, smoked eight to ten cigars and several always champagne at dinner, and with it all found time for a moderate amount of exercise, chiefly riding. In short, he lived the "hustling" life of Wall Street. He regarded himself as " hard as nails," nothing could hurt him. The ill effects of the night disappeared with the morning cold bath. He was always ready for his breakfast, and sharp as a hawk for business at 9 o'clock in the morning. Suclenly one day, without warning, after a heavy dinner, he lost the power of speech, and for nearly three dars was confused in his head and could not express himself intelligently. There was no paralysis of face or arm, and at the end of a week he was quite himself again. $A$ trace of albumen and a few tube casts were found in the urine, and he had a blood pressure of 212 . Of course this was a terrible shock. He gave up business, went to Carlsbad and a terrible shock. He gave up business, went to Carlsbad and He was still very apprehensive and worried, and had had a few attacks of pain about his heart after exertion. He was a big, attacks of pain about his heart after exertion. He was a big, healthy-looking man, of good colour and good physiyue. The pulse was 80 . Joth the radials and temporals could be rolled under the finger, and the pulse could be felt just as well on the distal side of the pressure. Compressing a section of the radial at a distance of $2 \mathrm{in}$. apart, the intervening portion of the vessel full of blood felt firm, and could be readily rolled under the finger. If, however, with gentle pressure, the bloor column was forced out of about $2 \mathrm{in}$. of the radial, its wall could not be felt or differentiated in any way from the tissues about it. The same held good for the temporal. With a about it. The same held good for the temporal with a similar experiment it was not easy to feel the wall of a brachial artery. The side the nipple line. The cardiac flatness was not increased. but there was a snapping, valvular aortic second sound. The systolic blood pressure was 235. No difference in the recum bent position and after exertion. The specific gravity of the urine was 1020 , and at times there had been a slight trace of albumen. There was none when I first saw him. There were no tube casts.

Here was a man whose arteries, as far as one could malio out, had not thickened palpably, certainly not beyond his age. His heart was not hypertrophied, but he had a very high blood pressure, and he had had one of those peculiar but not very uncommon attacks of aphasia in connexion with it.

It is interesting, sometimes distressing, to see a man of great vigour, in the prime of life, full of work and energy, in the first shock of the realization that he is a machine, with the works of which there is something radically wrong.

A fine strapping fellow of 48, a lawser of distinction, and among his friends a boon companion, full of work, public and private, suddenly noticed a slight obscurity of vision. As he was going off for his holiday in Europe he consulted an ophthalmic friend, who told him he had retinal haemorrhages and disease of his arteries. To a man who had never realized that his body was a mechanism it was a great shock to find himself "out of gear," and as he sail pathetically, "it did not seem the same world when I had to give up cigars, champagno and Scotch whisky, and pleasant evenings at the club." I saw him in July, 1909, the picture of health, and with the frame of him in July, 1909, the picture of health, and with the frame of a prize-fighter, but self-centred, nervous, apprehensive, worrying all the time lest another blood vessel might break. He had had a permanent blood pressure above 220 , records taken by a
dozen different doctors, and he had copies of the analysis of his dozen different doctors, and he had copies of the analysis of his
urine, and had provided himself with Theodore Janeway's book.

It is not always possible to suggest the factors causing the high blood pressure. It may be met with un expectedly and determined only by the apparatis; indeed one may feel a keen sense of disappointment that the educated finger should be so far astray. It may sometimes be the initial event in an inherited bias towardis cardio-vascular mischief, without the occurrence of any of the usual factors.

I saw this year, with Dr. Lichfield of Pittsburg, a healthy looking woman, aged 46, whose father, mother, several brothers, and a sister had died comparatively young of heart or arterial disease, and in whose family there vas marked gout. She ha!l herself been very bealthy, except for occasional " nervous attacks." She is stated to hare had congenital syphilis. She had had some pains in the muscles, rheumatic or gouty, anc Dr. Lichfield was astonished to find that her blood pressure
was above 200 . She was a well nourished, healthy looking was above 200. She was a well nourished, healthy looking woman, without luetic stigmata. The peripheral arteries were
nowhere sclerotic. The empty radial artery could not be felt. nowhere sclerotic. The empty radial artery could not be felt.
The temporals were not palpable. The heart impulse was not The temporals were not palpable. The heart impulse was not forcible, and the aortic second suund was not specially accentuated. 'To the touch I could not determine that the pressure was
high in the peripheral arteries, but it was above $200 \mathrm{~mm}$. The urine was of low specific gravity; no casts.

Where is the change in these cases? Not, so far as one can say, in the heart, not in the mains, not in the supply pipes, but to keep up a normal irrigation in the capillary beds there has to be a widespread increase of pressure in the smaller arteries. Where is the first link in the chain? In an altered condition of the vessels in the splanchnic arca? In a toxaemia from the bowels? In an oversecretion of pressor substanccs by renals and adreuals? More likely the block is in the irrigation fields. If the director of a large irrigation plant found the pressure rising in the supply pipes of the third and fourth dimensions, and there was nothing wrong in the pump or the sluices, he would go directly to the fields to see if the channels were free, and to see that the drainage was proportionate to the supply. I believe that in these cases the primary mischief lies between the capillary cell and the lympl spaces, in the working area of the body-a rov between the middle man, the manufacturers, and tho sanitary authorities - a sort of general strike, to overcome which the Government has to intervene. Remember, as I mentioned, vegetable physiology teaches plainly that the vis a fronte is a powerful factor in the metabolism of the cell, and it may be disturbances in this sphere that necessitate, as a conservative action, an increase in the pressuro with which the blood flows in the supply pipes. Or there is a difficulty in clearing of ashes and cinder the furnaces which keep up the fires of life in every unit of the bodily frame. The engines are stoked for the Glasgow express on the London and North-Western Railway, but put to work shunting empty trucks in the station yard! 
Cannon and others have shown that in emotional states there is an increase in the adrenal flow, and this is a factor which has to be considered in the high pressure of modern life. Understand one thing clearly-this high pressure is not itself the disease, but a compensatory, salutary state, if not for the man, at any rate for his circulation. That this is so, try to reduce it below a certain point. You may, for a time, but up it goes again, and the man only feels comfortable when you allow him to live at a certain high level. By diet, a change in the mode of life, etc., the pressure may be kept at a reasonable rate, but in my experience, never again does it fall to the normal. The first patient illustrates hor difficult or impossible it may be to permanently keep down the blood pressure. He had be sn at spas for special treatment; he had taken nitrites and potassium iodide; he had had " high frequency" treatment and a special course of sterilization of his colonbut all of no avail, as the pressure kept up. As he had become morbidly apprehensive and self-centred, I urged him to resume his business, lead a rational life, and stop talking " cures."

The disadvantages are: (1) Just such transient cerebral attacks as the first patient had, or headache, vertigo, flushings, or an anginal attack, or transient bouts of dyspnoea with palpitations. But more serious still is (2) the certainty that sooner or later sclerosis of the arteries will follow. And this brings me to the consideration of group II.

\section{Arterio-sclerosis with High Tension and Associated} Cardiac and Revil Chisges.

There are two essential factors in arterio-sclerosis-the quality of the tubing and the way in which it is treated. 'The marvel is that any set of pipes could be constructed to stand the continuous s'rain to which for years the human blood vessels are subjected. To use a well-worn simile-very different qualities of rubber are used in the make up of our tubing, and longevity is very much a matter of its quality, whether good Para or not. There is, too, that curious and inexplicable element which brings such uncertainty into our calculations. Take tro 1910 motor cars turned out from the same shops and by the same workmen and with the same parts. The one may give no trouble, the other may be half the time in the repair shops. Of a dozen blades of a Gillette safety razor, all identical in appearance and in fincness of edge, some may be used for weeks, even months; others may have to be cast aside in a few days. So it is with man and his blood vessels. The contract calls for from sixty to eighty years of usage. Some hold out woll, and even after ninety years are still fairly good, but the personal equation has always to be considered. The ordinary wear and tear of life may bring about arterial degeneration in a temperate man of 40 years; on the other hand, who has not seen lusty octogenarians with untouched hearts and arteries?

The commoner causes of arterio sclerosis need not detain us, toxic agents, chiefly, exogenous or, endogenous, some of them acting directly on the vessels, others by disturbing the circulation in the cell factories, calling for higher pressure in the supply pipes, and so leading indirectly to sclerosis

I should like to refer to two other causes, one of which has a note of personal appeal. There is an old motto, "It is the pace that kills," and nothing is more certain than that the pace of modern life lills many prematurely through the complications of arterio-sclerosis. The keen, sharp business or professional man, year in, year out giving his engines no rest, leading a life of high pressure, thongh a teetotaler and temperate in his diet, and a non smolier, may have so driven his machine that at 50 it is only fit to be scrapped. These tragedies of life are only too common among us. It is not only a great leader like William Pepper, who died an arterial death at 55, but we see it in the men who live the hard, unselfish lives of general practice. I have notes of at least a score of physicians wrecks before 50-men, too, who had enjoyed their work, untiring, unsparing of themselves and of their time-sensible fellows in everything but in the care of their machine. Some were victims of angina pectoris, some of myocarditis, others of progressive cardiac failure, many more of the complications of arterio-sclerosis-all of the high-pressure life too often nowadays the nezessary accompaniment-the penalty-of success. And $I$ think we must recognize another factor-prolonged overuse of the muscles. That athletes die early is well recognized, but it is not easy to determine always how far the cardiovascular changes are due to muscular effort alone. Take a not uncommon picture:

An exceedingly vigorous man, aged 50 , spare, weighing only 10 st., with a good family and a good personal history. He had never had syphilis, but at 28 he had had a bad attack of typhoil fever. He had lived an out-of-door life, and had used his muscles incessantly in sports as a young man, at cricket and hunting, and when at college as a long-distance runner; no gout in his family. He had been a moderate nser of alcohol and had smoked cigars and cigarettes, but not in excess. Four or five years ago he begain to have headaches, which hour or five years ago he began to have headaches, which have
bothered him at intervals ever since; but he has kept at work, bothered him at intervals ever since; but he has kept at work,
has played tennis and golf, and it was only a few months ago has played temmis and golf, and it was only a fer months ago that he consulted his doctor for the headlaches. A very healthy-
looking fellow, strong and muscular; his pulse was 80 -the looking fellow, strong and muscular ; his pulse was 80-the
vessel rolled easily under the fingers. The pulse was recurrent, vessel rolled easily under the fingers. The pulse was recurrent, and there was practically no difference as one felt the vessel
with the blood current in or when it was pressed out. The arteries were like whipcori. The temporals could be easily felt. The walls of the retinal arteries looked thick and they compressed the veins. The apex beat bulged the fifth interspace an inch and a half outside the nipple line $-a$ strong, forcible, and visible beat, localized in the one interspace. The shock of both sounds was palpable, and the shock of the aortic second sound so intense that it could be heard six or seven inches away from the chest wall. The first sound at the apex was booming, a little murmurish. The urine had a specific gravity of 1020 , and he did not pass an excessive amount; it showed a few hyaline casts. The blood pressure was 212 .

It is true the man had had typhoid fever, and a bad attack, but the arterial changes of the acute infections rarely take the form of a widespread sclerosis. I have notes of cases of angina pectoris in comparatively young men, not syphilitic, in whom the sole factor leading to coronary artery degeneration was persistent over. exertion.

As a rule men under 60 years of age with primary arterio-sclerosis have high blood pressure, indeed the highest known records are in this condition.

In this group of cases it is well to recognize that the extra pressure is a necessity-as purely a mechanical affair as in any great irrigation system with old encrusted mains and weedy channels. Yet the victims are often robust, energetic men of great vitality. Get it out of your heads, if possible, that the high pressure is the primary feature, and particularly the feature to treat. We tied up one evening near a big pumping station on the Nile, and in conversation the Scottish engineer in charge told me that the tro essential factors in maintaining uniformity in irrigation were keeping the terminal channels free between the rows of cane, an 7 maintaining the drainage. Obstruction in the fields could be overcome by increasing the pressure, to a certain point, but it was cheaper and safer to clear out the weeds. The difficulty, I believe, is to keep the human irrigation plant free from weeds, the sud that chokes the capillary bed, through which it takes a greater force to drive the fluids. We too often tinker at the pump and the mains, instead of looking for the real seat of trouble in the fields.

It is alarming to find that a patient may only be comfortable with a pressure about $200 \mathrm{~mm}$., but, as a rule, do not take too gloomy a view of the condition, which is often not so bad as it looks. For years a man may enjoy good health and do hard work with high-pressure, whipcord arteries and a hypertrophied heart. Take warning, pessimists, from this story:

I sarv on June 21st, 1901, a judge, aged 46, a man of good habits, except that he had been a very heavy eater. He had been very moderate in alcohol and tobacco, and had not has syphilis. He had taken a great deal of exercise, and had alway regarded himself as in the pink of condition. 1 year before saw him he began to have a little shortness of breath particularly if he played too much golf or went of breath, particuconsulted Dr. Delafield, who told or went uphill rapidly. He arteries Dr. Delatield, who told him he had sclerosis of the arteries and enlargement of the heart, and who urged him to hange his habits of life. He presented the usual picturemarkedly sclerotic arteries, very high blood pressure, a strong, orcible apex beat 3 in. by measurement outside the nipple line. The aortic second sonnd at the base was much accentuated. The specific gravity of the urine was high; no albumen, no tube casts. Now that did not look a very satisfactory condition in a comparatively young man who had never had syphilis nor any serious infections. He was a sensible fellow-cut down the intake of fuel, lived an easy life, attended to his duties, and has got on very comfortably. He called on me last summer unfortunately I was away, but a message on his card read: "Am feeling very fit"! 
"Judgement is difficult," says Hippocrates; but I never knew a man with so marked hypertrophy of the left ventricle to have an extension of life even beyond that granted to Hezelkiall. I do not think even the most optimistic wonld have given him fire years; Nature gave lim twenty!*

High tension is not always associated with arteriosclerosis, though present in a large majority of all patients nnder 60. Normal or low pressures may occur in threo conditions: (1) In elderly persons with extensive sclerosis of the aorta and its chief branches; (2) with a general failure of health and strength; and (3) in the late stages with the failing, dilated heart.

What is the condition of the lidneys in theso cases? This important question is not always easy to decide. In many instances the urine presents no abnormalities. There may be a trace of albumen, particularly in the morning, and a few tube casts, but the output is up to the mark, and certainly patients may for years have extreme nrterio-sclerosis without serious kidney disease. And post-mortcm studies show this to be the case. Witl permanent high tension alone, or with high tension plus nrterio-sclerosis, the kidneys have been found in a ferv cases practically normal. We must remember that no one at 50 has kidneys completely normal histologically. In the cases of chronic arterio-sclerosis which came to necropsy from my wards in the Johns Hopkins Hospital three types of kidneys were found.

1. The full-sized, hard, beefy organ, often with a smooth surface, sometimes with slight adhesion of the capsule, but an organ obviously not contracted. When I lived in Philadelphia a remarkable man was demonstrator of morbid anatomy at the university, and coroner's phy. sician, the late Dr. Formad. He had had a rich experience in medico-legal cases. I remember he brought before us the results of the study of the kidncys in some 250 cases of sudden death in alcoholics-176 men and 74 womenthe great majority of them above the middle period of life. .. Accurate figures were not given of the canses of death, but the interesting feature is that nearly all of these patients had somewhat enlarged, hard kidneys, frequently, too, of tho rounded, sausage-like or pig-backed form. Emerson's analysis of our cases of patients dying with features of general arterio-sclerosis showed that in 60 per cent. the combined weight of the lidneys was above 300 grams. The general experience is that in a very considerable proportion of all middle-aged persons with arterio-sclerosis the kidneys are not contracted.

2. The patchy arterio-sclerotic kidney, which presents atrophy of surface areas, or sometimes an extensive section of the end of one kidney, and everywhere showing the effects of irregular vascular' sclerosis.

3. The small, red, granular kidney, the final ontcome in a limited number of cases of renal arterio-sclerosis.

I need not divell upon this side of the question further than to ask you to bear in mind that conditions of chronic lyypertension and of advanced arterio-solerosis may exist without serious interference with the relial function.

Many of these patients have been condemned as cases of incurable Bright's disease without full knowledge. Fully fifteen year's ago I sav an old friend with slight swelling of the feet, cardiac wealness, retinal haemorrhages, traces of albumen in the urine, and tube casts. In a man of 60 who had worked very hard such a state certainly looked serious. He had stiff arteries and an accentuated aortic second sound. Though urged to retire, Jike a wise man he decided to slow the engines but to continue the royage. I saw him a few weeks ago, now a nan of 75, who mean while has travelled much, organized new departments of his work, and has been an actire, thongh not a vigorous man. On and off his ankles have Fiwollen and he has been short of breath on stairs and liills; but, like the ship in Kipling's Devil and the Deep Sca, with patched machinery lie has been able to keep up an 8 to 10 knot rate. I was interested to examine him carefully, and found his blood pressure above 180 ; cardiac impulse outside the nipple line and diffuse; the pulse regular, moderately stiff vessels, a small amount of albumen with tube casts in the urine, and in onc eve a fading retinal haemorrhage.

* Since giving this lecture, Dr. McCrae tells me of his leath-th usual way, gradual heart failure, with the distressing mental eymptoms so of ten seen.
III. Chroxic Nephritis with ARterio-scherosis aNd High Pressure.

Only a man of brazen boldness will speak dogmatically on this last, long and much-discussed group. That hyperpiesis may lead to arterio-sclerosis, that arteriosclerosis in turn may lead to sclerosis of the kidneys, that there are primary lesions of the kidney associated with fibrosis, which lead secondarily to high blood pressure, sclerosis of the arteries, and hypertrophy of the heart--these are points upon which most of us are agreed. Here, of the two important divisions - the chronic nephritis of the infections, and the nephritis of the intoxications, gout, lead, alcohol-the end-product in both mav be the small, hard, contracted lidneys. In a large proportion of all cases there are associated gradually hypertension, arterio-sclerosis, and hypertrophy of the heart. To distinguish between the two sets of cases, tho primary arterio-sclerotic and the primary nephritir, is not often difficult. In the infectious group the history is generally very distinct, the patients are younger, and they rarely have the seneral vigour of the arterio-sclerotic form. In the lead and gout toxaemias one is rarely in doubt, though in the latter the et:ology is often overlooked. On the other hand, the urinary changes in both differ from the arterio-sclerotic form in the persistent low specific gravity, the lower nitrogen output, the more coustant presence of albumen' (though in slight amount) and the persistence of granular casts. The symptoms, too, are renal and cercbial in the nephritic group, cardiac in the arterio-sclerotic. Uraemic features, progressive pallor, headaches, and marked ocular changes are very much more com. mon in the primary nephritic form, and the retinal changes are degenerative, not simply haemorrhagic. There are transitional stages, and the end of the arterio-sclerotic kidney may be small, red and granular. Intercurrent acute or subacute attacks of nephritis may at any time blur the picture. I have not infrequently been mistaken, led astray usually by the robustness of the patient, and forgetting that chronic interstitial nephritis leading to extreme contraction of the organ may be consistent with good health up to the very onset of fatal uraemic convulsions. In this nephritic class we see remarkable variations in the arterial tension, persistently ligh in some cases, in others quite moderate, though with extreme artcrio-sclerosis and hypertrophy of the left ventriclc. The hypertersion, doubtless compensatory, and so far as it goes salutary, is caused possibly by increased discharge of pressor substance, and in any case is imperative in the irrigation fields of kidneys choked with débris and overgrown with the weeds of con. nective tissue growtl. The disadvantages are obvious when the chronic hypertension leads to arterial degeneration and renders the patient liable to rupture of the cerebral vessels - a common mode of death in these cases. Careful study of the blood pressure is demanded in tho form in which we see hypertensive crises associated with severe headache, often the precursor of uracmia or of transient aphasia with or without paralysis, attacks which a timely bleeding; or purge, or a sweat may ward off.

Lastly, a few words on the care of these cases. Differ. ing as they do so much in etiology and symptoms, a thorough study of each patient is required. At the same time do not lay too much stress upon the hypertension, particularly in nerrous patients. When the first intimation comes in the form of an angina, or of a cerebral attack, a man naturally becomes very apprehensive. Patients easily become hipper on the subject of blood pressure; ono man had his records carefully charted for cightecn months, and talked like a lay Marey on the various methods. I am not sure whether he was consoled or disappointed to be assured that it was a very good thing for him that his engines had liept up a pressure of about $180 \mathrm{~mm}$.

I.

The first thing is to determine the nature of the case, whether simple hypertension, arterio-sclerosis, or chronic nephritis, or all combined. In the cisse of the active, driving, business man, who has unconsciously damaged the machine, let him reduce the speed from the twenty-four linots of a Lusitania to the ten linots of the ocean tramp. It is interesting to note that the worry and apprehension associated with the first shock of the discovery that something is wrong may cause loss of weight and with it reduction in the blood pressure. $A$ man of 62 , 
whose first indication of trouble was an attack of transient aphasia, lost 2 st. in weight in a year, and his blood pressure sank from 200 to 150 . He has been better since he has taken a philosophical view of the situation, and his blood pressure has risen to 180.

\section{II.}

The second thing is to lessen the intake. We all eat too much, and in no age was the saying more true that "the platter kills more than the sword." Time and again I have been impressed with this as a possible factor in obscure forms of hypertension and arterio-sclerosis in persons otherwise temperate. Largely a matter of labit, the amount of food taken should be just enough to keep the engines going at a steady speed. A diet of low protrin content is best, and fairly large quantities of liquid should be taken.

III.

Thirdly, elimination should be promoted in every way, by making the action of the kidneys, bowels, and skin thoroughly efficient.

\section{IV.}

Fourthly, of drugs none are entirely satisfactory in chronic hypertension. Nitrites in various forms may be used, and are often of temporary benefit, but $I$ think the general opinion now is that neither the nitrites nor potassium iodide are of permanent benefit; though now and again one meets with an instance in which the prolonged used of potassium iodide is followed by marked lovering of the pressure. A preparation of mistletoe has also been much lauded, but it, too, is very variable in its effects. Be careful in this point-if the patient does not feel so well, and begins to get thin and look badly, stop all drugs, trust to general measures, and let the pressure ris?. In the robust man of full habit in the hypertensive crises with headaches, dyspnoea, or angina, a free vene saction is indicated, to be followed by mercurial and saline purges.

The clinical picture which I have thus briefly sketched of chronic hypertension with its associations, advantages, and disadvantages, may not have all the outlines or full details which an artist with more pains and greater skill would put on his canvas, but it is a fair presentation of the subject as I have seen it, and you cannot expect more The colours, necessarily a bit sombre, have been brightened when possible. And I believe Candide to be wrong-life at the best is not a bad bargain. Even the victim of high tension may find it useful and enjoyable if, following the rest of the moral, he will cultivate his garden-weeding the irrigation channels, and keeping free the drainage.

\section{THE CALCULATION OF DRUG DOSAGE FOR CHILDREN.}

\section{IITTH DESCRIPTION OF A NEW AND SIMPLE METHOD.}

By WALTER J. DILling, M.B., Сн.B.,

LECTURER IN PHARMACOLOGY, ABERDEEN UNIVERSTTY.

The calculation of the correct dosage of drugs which are to be administered to children is of considerable importance. The systems at present in use are those of Young, Gabius, and Cowling, all of which are based on the duodecimal system, and are thus not readily applicable to the m stric system; Sir Lauder Brunton's method of calculating from the metric system involves perhaps rather more mental calculation than can be expected of the practitioner when prescribing at the bedside, and further, it does not lend itself to the calculation of doses from the imperial system.

These four systems may be stated briefly: Young's formula is the age of the child divided by the age plus 12 ; according to Gabius, the correct dosage-taking 1 grain as the adult dose - is for a child 1 year old, 1 grain; 2 years old, $\frac{1}{8}$ grain; 3 years old, $\frac{1}{6}$ grain ; 4 years old, $\frac{1}{4}$ grain ; 7 years old, $\frac{1}{3}$ grain; 14 years old, $\frac{1}{2}$ grain; 20 years old 2 grain ; and above 21 years, the full dosage. Cowling's rule is the division by 24 of the child's age at his next birtbday; and Sir Lauder Brunton's plan consists in using the age next birthday as the numerator and 25 as the denominator of the fraction.
Apart from idosyncrasy, abnormal development, and tise excessive susceptibility to certain drugs, such as opium, a rational system for calculating dosage in children should follow the curve of increase in body weight; that is to say, we must supply the child with the same relative dose of the drug in proportion to his bulk as we supply to the adult, or, in other words, the dilution of the drug in the body tissues should be the same in both cases. It is, how. ever, impracticable to weigh each infant before writing its prescription, and we therefore adopt the age as an indication of the development and weight of the average child and its abilities to tolerate drugs. Gabius assumes the adult age to be 21, while Cowling and Sir Lauder Brunton postpone it till 24 and 25 respectively. It may, I think, be assumed th it the ages 24 and 25 were selected, not on account of any particular anatomical or physsiological reason, but because of the fact that they were numbers easily divisible on the duodecimal and metric systems respectively. If statistical tables of the average weights of males and females be examined it will be noticed that the body weight becomes stationary on an average at from 20 to 22 in males and from 19 to 20 in females. Thus, we find that the average adult age according to the weight is from 20 to 21 years. These tigures I have arrived at by averaging the results of statistics by Quételet, Landois, Beneke, and Roberts, the last-named having obtained his data from English-speaking clildren, who are relatively much heavier than Continental children. Whichever series of weight statistics is adopted, it makes little difference to the final results, since we are concerned with the relation of the child's weight at a certain age to his probable adult weight. The following table-taken, since we are dealing with English children, from Roberts's tables-will illustrate the points to which references have been made:

\begin{tabular}{|c|c|c|c|c|c|}
\hline \multirow{3}{*}{ Age. } & \multirow{2}{*}{\multicolumn{2}{|c|}{$\begin{array}{c}\text { Average Kilogram } \\
\text { Weights. } \\
\cdot\end{array}$}} & \multicolumn{3}{|c|}{$\begin{array}{l}\text { Proportions to the Average Adult } \\
\text { Weight. }\end{array}$} \\
\hline & & & \multicolumn{2}{|c|}{ Male. } & \multirow{2}{*}{$\begin{array}{c}\text { Female. } \\
\begin{array}{r}\text { Adult Age } \\
21 \text { or } 24 \\
\frac{3.13 \times 100}{55}\end{array}\end{array}$} \\
\hline & Male. & Female. & $\begin{array}{c}\text { Adult Age } \\
\text { as 21 } \\
\frac{3.22 \times 100}{65.7}\end{array}$ & $\begin{array}{c}\text { Adult Age } \\
\text { as } 24 \\
3.22 \times 100 \\
67\end{array}$ & \\
\hline Birth & 3.22 & 3.13 & 4.90 & 4.80 & 5.69 \\
\hline 1 & 10.89 & 9.12 & 16.59 & 16.25 & 16.58 \\
\hline 2 & 14.75 & 11.48 & 22.45 & 22.01 & 20.87 \\
\hline 3 & 15.42 & 14.35 & 23.47 & 23.01 & 26.09 \\
\hline 4 & 16.92 & 16.39 & 25.90 & 25.25 & 29.80 \\
\hline 5 & 18.14 & 17.78 & 27.59 & 27.07 & 32.32 \\
\hline 6 & 20.15 & 19.05 & 30.66 & 30.07 & 34.64 \\
\hline 7 & 22.68 & 21.55 & 34.52 & 33.85 & 39.18 \\
\hline 8 & 24.95 & 23.54 & 37.95 & 37.24 & 42.80 \\
\hline 9 & 27.40 & 25.17 & 41.70 & 40.89 & 45.76 \\
\hline 10 & 30.62 & 28.12 & 46.60 & 45.70 & 51.13 \\
\hline 11 & 32.66 & 30.90 & 49.70 & 48.74 & 56.18 \\
\hline 12 & 34.93 & 34.66 & 53.16 & 52.13 & 63.02 \\
\hline 13 & 37.66 & 39.55 & 58.84 & 56.21 & 71.99 \\
\hline 14 & 41.73 & 44.00 & 63.51 & 62.28 & 80.00 \\
\hline $15^{\circ}$ & 46.68 & 48.18 & 70.83 & 69.67 & 87.60 \\
\hline 16 & 53.94 & 51.31 & 82.09 & 80.50 & 93.29 \\
\hline 17 & 59.38 & 52.35 & 90.38 & 88.62 & 95.18 \\
\hline 18 & 62.28 & 54.89 & 94.79 & 92.95 & 99.80 \\
\hline 19 & 63.46 & 56.21 & 96.59 & 94.71 & 102.20 \\
\hline 20 & 64.96 & 55.93 & 98.87 & 96.95 & 101.69 \\
\hline 21 & 65.73 & 55.20 & 100.00 & 98.10 & 100.36 \\
\hline 22 & 67.09 & 55.93 & & 100.00 & 101.69 \\
\hline 23 & 67.09 & 56.25 & & 100.00 & 102.27 \\
\hline 24 & 67.09 & 54.85 & & 100.00 & 99.73 \\
\hline
\end{tabular}

